\title{
Circulating Levels of Biologically Active and Immunoreactive Intact Parathyroid Hormone in Human Newborns
}

\author{
LEWIS P. RUBIN, JAMES $T$. POSILLICO, CONSTANTINE S. ANAST,' AND \\ EDWARD M. BROWN \\ Departments of Pediatrics and Medicine, Harvard Medical School; Department of Newborn Medicine [L.P.R.] \\ and Endocrine-Hypertension Unit [J.T.P., E.M.B.], Brigham and Women's Hospital; and Division of \\ Endocrinology [L.P.R., C.S.A.], The Children's Hospital, Boston, Massachusetts 02115
}

\begin{abstract}
We evaluated circulating levels of biologically active and immunoreactive intact parathyroid hormone [iPTH-(1-84)] in 47 newborns at birth and eight hypocalcemic preterm infants during the first $10 \mathrm{~d}$ of life. Use of two sensitive detection systems, the cytochemical bioassay and an immunoradiometric assay specific for intact parathyroid hormone, enabled us to compare plasma concentrations of PTH-like bioactivity (bioPTH) and iPTH-(1-84). Mean umbilical venous plasma bioPTH was elevated in nondiabetic term and preterm newborns [22.5 $\pm 3.1( \pm$ SEM) and $15.8 \pm 2.5 \mathrm{ng}$-equiv/L, respectively] compared with normal adult subjects $(9.8 \pm 2.6$ ng-equiv/ $\mathrm{L} ; \boldsymbol{p}<0.01$ ). Umbilical bioPTH was suppressed in five term infants of diabetic mothers $(2.6 \pm 0.4 \mathrm{ng}$-equiv/L). In contrast, iPTH-(1-84) was low in term and preterm nondiabetic infants' and term infants of diabetic mothers' umbilical samples $(5.4 \pm 1.5,4.3 \pm 1.5$, and $2.4 \pm 1.0 \mathrm{ng} /$ $\mathrm{L}$, respectively). Umbilical venous bioPTH was highly correlated with the magnitude of the transplacental calcium gradient $(r=0.90 ; p<0.05$ ). In eight preterm infants studied longitudinally, by $24-36 \mathrm{~h}$ of life, declining plasma total and ionized calcium $(1.71 \pm 0.04$ and $0.78 \pm 0.03$ mmol/L, respectively) were accompanied by a significant rise in both bioPTH (41.2 $\pm 6.3 \mathrm{ng}$-equiv/L) and $\mathrm{iPTH}-(1-$ 84) $(56.3 \pm 11.6 \mathrm{ng} / \mathrm{L})$. These data indicate that the 3rd trimester fetoplacental circulation contains levels of bioPTH several-fold higher than those of immunoreactive intact hormone. We also conclude that even hypocalcemic preterm newborn infants can significantly elevate circulating levels of PTH. (Pediatr Res 29: 201-207, 1991)
\end{abstract}

\section{Abbreviations}

PTH, parathyroid hormone

iPTH-(1-84), immunoreactive intact parathyroid hormone bioPTH, parathyroid hormone-like biologic activity

IDM, infant of a diabetic mother

$\mathrm{Ca}_{\mathrm{T}}$, total calcium concentration

$\mathrm{Ca}_{1}$, ionized calcium concentration

CBA, cytochemical bioassay

G6PD, glucose 6-phosphate dehydrogenase

DCT, distal convoluted tubule

PTHrP, parathyroid hormone-related peptide

Received June 14, 1990; accepted October 2, 1990.

Correspondence and reprint requests: Lewis P. Rubin, M.D., Department of

Pediatrics, Women \& Infants' Hospital, 101 Dudley Street, Providence, RI 02905.

Supported in part by USPHS Grants K08-HD00861 and R01-AM36796.

'Deceased.
In humans and other mammals, the extracellular total and ionized calcium concentrations change dynamically during the transition from fetal to extrauterine life. The fetal circulation of mammals in the 3rd trimester is hypercalcemic relative to that of the mother. In humans, cessation of transplacental flow of calcium at birth is associated with decrements in $\mathrm{Ca}_{\mathrm{T}}$ and $\mathrm{Ca}_{1}$ concentrations. Blood calcium stabilizes 1 to $2 \mathrm{~d}$ after birth, then rises progressively to levels observed in older children and adults. An exaggeration of this sequence of events, early neonatal hypocalcemia $\left(\mathrm{Ca}_{\mathrm{T}}<1.75 \mathrm{mmol} / \mathrm{L} ;<7.0 \mathrm{mg} / \mathrm{dL}\right)$, occurs in at least 35 to $50 \%$ of preterm newborn infants $(1,2)$ and more than $90 \%$ of extremely preterm infants (3).

Inference from other hypercalcemic states has suggested that the chronic hypercalcemia of late fetal existence might suppress fetal PTH secretion (4) and that neonatal parathyroid suppression might persist for several days postpartum, blunting the PTH secretory response to a declining extracellular calcium $(4,5)$. A corollary of this hypothesis suggests that the more severe, early neonatal hypocalcemia of preterm babies might result from a transient functional hypoparathyroidism.

Unfortunately, interpretation of levels of immunoreactive PTH measured to date has been hampered both by the immunoheterogeneity of circulating hormone and the preponderance of biologically inactive fragments. Moreover, biologically active PTH circulates in normal subjects at picomolar concentrations $(6,7)$, which, until recently, have been beyond the detectability of most assay systems. It is not surprising, then, that iPTH in fetal and umbilical cord blood has been reported as indeterminate or low in some series $(5,8-14)$ and normal, or even elevated, compared with maternal or other adult levels $(4,15-18)$ in others. A variety of iPTH levels have also been reported in association with early neonatal hypocalcemia $(1,3,12,19)$.

Using the ultrasensitive CBA for PTH developed by Chambers (20), Care et al. $(21,22)$ showed that bioPTH in porcine fetal plasma exceeds paired maternal plasma bioPTH. Similarly, Allgrove et al. (14) reported that human term umbilical cord plasma bioPTH is elevated 5- to 6-fold above paired maternal plasma bioPTH and significantly exceeds values determined in normocalcemic adults.

In this report, we have extended these studies by comparing circulating levels of PTH during the perinatal period by means of 1) the PTH CBA and 2) a newer, very sensitive immunoradiometric assay specific for intact PTH (Allegro, Nichols Institute Diagnostics, San Juan Capistrano, CA).

\section{MATERIALS AND METHODS}

Subjects. The subjects in this report included 47 newborn infants delivered at Brigham and Women's Hospital, Boston, MA. Of these, 17 were the products of normal term pregnancies, 
25 were delivered prematurely (26-36 wk gestation), and five were the term offspring of diabetic mothers (White's classification B or greater) (23). Thirty of the mothers were white, 12 were black, and two Asian. The birth weights of all term and preterm infants and three of the IDM were appropriate for gestational age. The other two IDM were large for gestational age. The immediate causes for preterm birth were preterm labor $(n=21)$ or hypertensive disorders of pregnancy $(n=4)$. Three sets of preterm twins were studied. Infants of mothers who had received magnesium infusions and infants with either documented or strongly suspected sepsis or perinatal asphyxia or with congenital anomalies were excluded. Gestational age was assessed by the date of last menstrual period, first trimester sonographic evaluation when available, and physical criteria (24). Physical examinations for all infants studied were performed by the same investigator. Only infants for whom two or more gestational age criteria were concordant ( $\leq 2 \mathrm{wk}$ difference) were included. Last menstrual period and 1st trimester ultrasound were available for five of the 17 term infants, 10 of the 25 preterm infants (including all multiple gestations), and all five IDM. Otherwise, the specific criteria used for gestational age assessment were physical examination and last menstrual period for nine term and 11 preterm babies, and physical examination and sonogram for the remaining three term and four preterm babies.

Blood samples were obtained from umbilical vessels immediately after cord clamping and before delivery of the placenta. In a subgroup of eight preterm infants, longitudinal blood samples were also obtained at $24(n=4)$ or $36 \mathrm{~h}(n=4)$ and at 7 to 10 $\mathrm{d}$ postpartum via indwelling arterial catheter or by venipuncture. Blood specimens were drawn into cold heparinized tubes as well as into tubes without anticoagulant and then centrifuged at $4^{\circ} \mathrm{C}$ within $30 \mathrm{~min}$ of collection. Aliquots of plasma and serum were stored at $-70^{\circ} \mathrm{C}$ for subsequent analysis. Venous blood samples also were obtained from six normocalcemic adult volunteers (three nonpregnant females, three males) and five parturient women and similarly processed. We have previously reported bioPTH and iPTH-(1-84) values for these five parturient women (25). Patient recruitment and parental informed consent protocols were approved by the Committee for the Protection of Human Subjects of the Brigham and Women's Hospital. Parental consent was obtained for all babies studied.

Assay methods. CBA was performed as reported previously by Chambers et al. (20) and Fenton et al. (26) with minor modifications (27). The assay procedure is based on the time- and dosedependent stimulation of G6PD activity by PTH in guinea pig renal cortical cells. Vitamin D-supplemented female Hartley strain albino guinea pigs, weighing 450-550 g, were killed and the kidneys removed and decapsulated. Renal cortical segments (approximately 5-7 $\mathrm{mm}$ in all dimensions) were preincubated for $5 \mathrm{~h}$ at $37^{\circ} \mathrm{C}$ in nonproliferative synthetic culture medium (Trowell's T8 medium; Grand Island Biological Company, Grand Island, NY) at pH 7.6 in an atmosphere of $95 \%$ air and $5 \% \mathrm{CO}_{2}$. After further incubation in fresh medium for $10 \mathrm{~min}$, each segment was cultured for 6 min with one of the following: 1) graded doses of human PTH-(1-84) reference standard (code 79/500, National Institute for Biological Standards and Controls, London, England), 2) dilutions of plasma samples (1:100 or 1:1000), or 3) dilutions of synthetic purified human PTH-(1-84) in human serum $(1: 100$ or $1: 1000)$ (Nichols Institute Diagnostics). All dilutions were performed with Trowell's T8 medium containing $1 \%$ outdated blood bank plasma previously stripped of PTH with QUSO-32 microfine silica $(10 \mathrm{mg} / \mathrm{mL}$ ) (Philadelphia Quartz Co., Valley Forge, PA). Segments were chilled by immersion in hexane on dry ice and stored at $-70^{\circ} \mathrm{C}$ for $1-3 \mathrm{~d}$. Unfixed frozen crystat sections $(8 \mu \mathrm{m})$ were cut from just below the cortical surfaces at $-12^{\circ} \mathrm{C}$ and then reacted for G6PD activity in $5 \mathrm{mM}$ glucose 6-phosphate, $3 \mathrm{mM}$ NADP, $0.67 \mathrm{mM}$ phenazine methosulfate, $5 \mathrm{mM}$ tetrazolium chloride, $10 \mathrm{mM}$ potassium cyanide, and $20 \%$ polyvinyl alcohol in $0.05 \mathrm{M}$ glycyl glycine buffer, $\mathrm{pH}$ 8.0. Juxtaglomerular DCT cells were identified by morphologic and, in parallel sections, cytochemical criteria (20). The intensity of the formazan reaction product within DCT cells was measured by microdensitometry (Zeiss) at $589 \mathrm{~nm}$ with an $8-\mu \mathrm{m}$ mask. The mean absorbancy value for each incubation sample (PTH standard or unknown) was calculated from measurements obtained at 10 to 20 different DCT fields within the same section. Readers were blinded to the identity of the sections.

For immunoabsorption studies, samples were incubated with antibovine PTH guinea pig serum (AS 211/41, Wellcome Research Laboratories, Beckenham, England) for $30 \mathrm{~min}$ at $4^{\circ} \mathrm{C}$ at a final dilution of 1:5000 before bioassay. This antiserum displays specificity for both human N-terminal (1-34) and C-terminal (53-84) PTH. Cross-reactivity of the antiserum for PTHrP was determined by spiking Quso-stripped human plasma with either synthetic human PTH-(1-34) or PTHrP-(1-34) (Bachem, Torrance, CA) at concentrations of $50 \mathrm{ng} / \mathrm{L}$ (approximately $12 \mathrm{pmol} /$ L) and performing immunoabsorption experiments as described above. Preincubation with this antiserum extinguished $99 \%$ of the cytochemical bioactivity of authentic PTH and only $9.5 \pm$ $3.8 \%(n=5)$ of the bioactivity of authentic PTHrP.

In several assays, we compared the relative bioactivities of the National Institute for Biological Standards and Controls and Nichols Institute human PTH-(1-84) standards. Both standards were also compared in parallel in the immunoradiometric assay. Our aliquots of National Institute for Biological Standards and Controls PTH possessed $71 \pm 2 \%$ of the activity of equimolar amounts of the Nichols Institute standard. For facility of comparison, all CBA and immunoradiometric PTH data were normalized to a single (Nichols) human PTH-(1-84) standard. CBA results were expressed as ng-equiv/L relative to human $\mathrm{PTH}-(1-$ $84) ; 1 \mathrm{ng} / \mathrm{L}$ of human PTH-(1-84) is equivalent to $106.1 \mathrm{fmol} /$ L. The intraassay coefficient of variation for the CBA was $9.0 \%$ and the interassay coefficient of variation was $15 \%$ (determined in a normal human plasma pool sample over a $2-y$ period).

Serum intact PTH was determined in duplicate using the Allegro immunoradiometric assay (Nichols Institute). This technique is a two-site immunoradiometric assay, with two different affinity-purified goat polyclonal antisera to human PTH, one binding the midregion and C-terminal portion of PTH (residues 39-84) and the second binding the N-terminal region of PTH (residues 1-34); the latter is radiolabeled with ${ }^{125}$ I. The sensitivity of the assay in our laboratory was $1 \mathrm{ng} / \mathrm{L}(\sim 0.1 \mathrm{pmol} / \mathrm{L})$, and it is believed to quantify accurately the intact form of PTH [PTH(1-84)] (28). PTH-(1-34) fragments do not cross-react in this assay at concentrations up to $300 \mathrm{ng} / \mathrm{L}$, and PTH fragments 39$68,53-84,44-68$, and 39-84 do not cross-react at concentrations up to $100000 \mathrm{ng} / \mathrm{L}$. In our laboratory, the intra- and interassay variations for this system were 2.6 and $5.8 \%$, respectively.

Plasma $\mathrm{Ca}_{\top}$ and $\mathrm{Ca}_{1}$ levels were assayed using a NOVA-7 calcium analyzer (NOVA Biomedical, Waltham, MA). Plasma magnesium and phosphorus concentrations were determined in the clinical chemistry laboratory. Magnesium concentrations were determined by atomic absorption spectrometry (interassay coefficient of variation $=5.2 \%$ ) and phosphorus was determined by standard photometric methods using a DuPont analyzer (interassay coefficient of variation $=2.6 \%$ ).

Statistical analysis. Descriptive data are expressed as the mean \pm SEM. Because the assay data groups are not normally distributed, nonparametric statistics (Wilcoxon's signed rank test and two-way analysis of variance) were used for intergroup comparisons. For purposes of analysis, undetectable iPTH-(1-84) values were treated as the lowest values detectable in the immunoassay $(1 \mathrm{ng} / \mathrm{L})$. Correlations were performed using linear regression and Pearson's correlation coefficient. The null hypothesis was rejected when $p<0.05$ was obtained. Certain statistical analyses used SAS-PC (SAS Institute, Cary, NC).

\section{RESULTS}

PTH-like bioactivity and calcium concentrations in umbilical cord blood specimens. Circulating levels of plasma bioPTH in 
infants at the time of birth are shown in Figure 1. Umbilical venous plasma bioPTH for the term and preterm newborns and term IDM were $22.5 \pm 3.1,15.8 \pm 2.5$, and $2.6 \pm 0.4$ ng-equiv/ $\mathrm{L}$, respectively. The mean value for preterm infants was not significantly less than that for term babies, whereas that for IDM was significantly less than that for the other groups $(p<0.01)$. Umbilical venous and umbilical arterial bioPTH did not differ significantly ( $36.4 \pm 9.6$ versus $34.9 \pm 8.6$ ng-equiv/L, $n=3$ ).

The mean bioPTH concentration for six normocalcemic young adults studied concurrently was $9.8 \pm 2.6 \mathrm{ng}$-equiv/L. We recently reported that maternal bioPTH (drawn within 30 min before birth) in five mothers of term infants from this study was $7.7 \pm 2.3 \mathrm{ng}$-equiv/L (25), which is equivalent to $5.6 \pm 1.6 \mathrm{ng}-$ equiv/L normalized to the synthetic human PTH-(1-84) standard described in Materials and Methods. This value is similar to that for nonpregnant adults. For term and preterm infants, mean

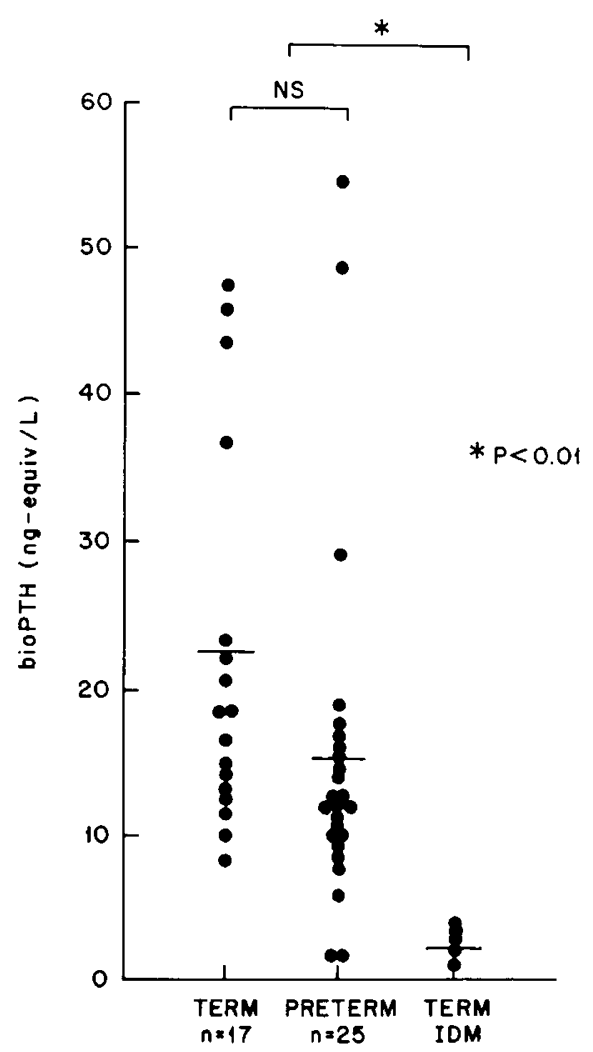

Fig. 1. Umbilical venous bioPTH levels in nondiabetic term and preterm infants and term IDM. The mean values (horizontal bars) of bioPTH in the nondiabetic term and preterm newborns did not differ significantly. The mean value of the IDM is significantly lower $(p<$ $0.01)$ than the mean values of the nondiabetic infants. Nanogramequivalents of bioPTH are converted to pmol-equivalents by multiplying by 0.1061 .

Table 1. Umbilical venous plasma mineral concentrations in term and preterm infants and term IDM*

\begin{tabular}{lccc}
\hline & Term & Preterm & Term IDM \\
\hline $\begin{array}{l}\text { No. of subjects } \\
\text { Total calcium } \\
(\mathrm{mmol} / \mathrm{L})\end{array}$ & 17 & 25 & 5 \\
$\begin{array}{c}\text { Ionized calcium } \\
(\mathrm{mmol} / \mathrm{L})\end{array}$ & $1.39 \pm 0.03$ & $1.35 \pm 0.02$ & $1.33 \pm 0.05$ \\
$\begin{array}{c}\text { Total magnesium } \\
(\mathrm{mmol} / \mathrm{L})\end{array}$ & $0.83 \pm 0.02$ & $0.81 \pm 0.01$ & $0.76 \pm 0.02$ \\
\end{tabular}

* Values are the mean \pm SEM.

$\dagger p<0.005$ vs the nondiabetic term group.

$\ddagger p<0.05$ vs the aggregate nondiabetic (term and preterm) group. umbilical bioPTH was significantly higher than the values in both normal adults $(p<0.01)$ and mothers $(p<0.05)$.

Plasma $\mathrm{Ca}_{\mathrm{T}}, \mathrm{Ca}_{\mathrm{I}}$, and total magnesium concentrations for the term and preterm babies and IDM are shown in Table 1. Total calcium concentrations for the IDM were significantly lower than the $\mathrm{Ca}_{\mathrm{T}}$ for the nondiabetic term infants $(p<0.005)$ and for all nondiabetic infants $(p<0.05)$.

When paired maternal-neonatal samples that were drawn simultaneously were compared, umbilical cord bioPTH and calcium exceeded the maternal values in each case (Fig. 2). Thus, the relatively elevated level of umbilical venous bioPTH in normal infants at birth exists in the face of mild umbilical plasma hypercalcemia. When a polyvalent antiserum against PTH was added to umbilical plasma before CBA, $88 \pm 3 \%$ of bioactivity was quenched ( $n=3$ ) (Fig. 3). Preincubation of plasma from 1to 2-d-old neonates with the same antiserum eliminated essentially all activity in the CBA $(97 \pm 1 \%)$.

No correlation could be demonstrated between umbilical plasma bioPTH values and cord $\mathrm{Ca}_{\mathrm{T}}$ and $\mathrm{Ca}_{1}$, gestational age, fetal gender, or mode of delivery. A significant correlation was seen, however, between cord bioPTH and the transplacental gradient of calcium between paired maternal-neonatal samples $(r=0.90, p<0.05)$ (Fig. 4). A similar relationship has been observed by Allgrove et al. (14).

iPTH-(1-84) in umbilical cord specimens. Figure 5 depicts serum concentrations of iPTH-(1-84), which were determined for the population of umbilical venous samples. Umbilical serum iPTH-(1-84) was suppressed $(5.4 \pm 1.5 \mathrm{ng} / \mathrm{L}$ for term and $4.3 \pm$ $1.1 \mathrm{ng} / \mathrm{L}$ for preterm babies) and significantly differed from umbilical plasma bioPTH $(p<0.001)$. Umbilical iPTH-(1-84) in IDM was similarly suppressed $(2.4 \pm 1.0 \mathrm{ng} / \mathrm{L})$. For the five maternal-newborn pairs assayed, the maternal iPTH-(1-84) values were always greater (Fig. $2 c$ ).

Relationships between bioPTH and intact PTH levels and calcium concentrations in early neonatal hypocalcemia. In the eight preterm babies studied longitudinally, $\mathrm{Ca}_{\mathrm{T}}$ declined from $2.58 \pm 0.04 \mathrm{mmol} / \mathrm{L}$ in cord plasma to $1.71 \pm 0.04 \mathrm{mmol} / \mathrm{L}$ by 24-36 $\mathrm{h}$ after birth. By d 7-10, plasma $\mathrm{Ca}_{\mathrm{T}}$ rose significantly $(2.13 \pm 0.08 \mathrm{mmol} / \mathrm{L}$ ) (Fig. 6). During the study interval, cord $\mathrm{Ca}_{1}(1.38 \pm 0.05 \mathrm{mmol} / \mathrm{L})$ also declined $(0.78 \pm 0.03 \mathrm{mmol} / \mathrm{L})$ and then rose $(1.02 \pm 0.04 \mathrm{mmol} / \mathrm{L})$, paralleling the directional changes seen for $\mathrm{Ca}_{\mathrm{T}}$. These magnitudes of change in total and ionized calcium are similar to those observed by others in hypocalcemic preterm babies $(29,30)$. Among our group of eight preterm babies, six met the criterion for early neonatal hypocalcemia of $\mathrm{Ca}_{\mathrm{T}}<7.0 \mathrm{mg} / \mathrm{dL}(<1.75 \mathrm{mmol} / \mathrm{L})$. The other two infants $\left(\mathrm{Ca}_{\mathrm{T}}\right.$ of 1.82 and $1.77 \mathrm{mmol} / \mathrm{L}$, respectively, at $\left.36 \mathrm{~h}\right)$ both exhibited $\mathrm{Ca}_{\mathrm{T}}<1.75$ at the time of 24 -h routine (nonstudy) blood sampling. $\mathrm{Ca}_{\mathrm{T}}$, however, did not predict $\mathrm{Ca}_{\mathrm{I}}$. During the period examined in this study, changes in magnesium and phosphorus did not reach significance (data not shown).

BioPTH and iPTH-(1-84) also were assayed longitudinally in these preterm babies (Fig. 6). Both measures of PTH increased significantly from the time of birth to $24-36$ postnatal h $(41.2 \pm$ 6.3 ng-equiv/L and $56.3 \pm 11.6 \mathrm{ng} / \mathrm{L})$. By $7-10 \mathrm{~d}$ after birth, bioPTH $(5.3 \pm 1.9$ ng-equiv/L) and iPTH-(1-84) $(14.1 \pm 3.5 \mathrm{ng} /$ $\mathrm{L})$ again declined. This rise and decline of PTH coincides temporarily with the observed decline and subsequent rise in $\mathrm{Ca}_{\Upsilon}$ and $\mathrm{Ca}_{\mathrm{I}}$.

In the babies studied longitudinally, umbilical bioPTH (17.1 \pm 5.3 ng-equiv/L) significantly exceeded cord iPTH-(1-84) $(4.4$ $\pm 1.8 \mathrm{ng} / \mathrm{L})(n=8 ; p<0.05)$, as was the case for the population of all cord samples. In the postnatal specimens, on the other hand, iPTH-(1-84) exceeded bioPTH on both d 1-2 and 7-10. Similarly, in the maternal samples, iPTH-(1-84) was greater than bioPTH $(12.9 \pm 1.5 \mathrm{ng} / \mathrm{L}$ versus $5.6 \pm 1 \mathrm{ng}$-equiv/L, respectively). 
a

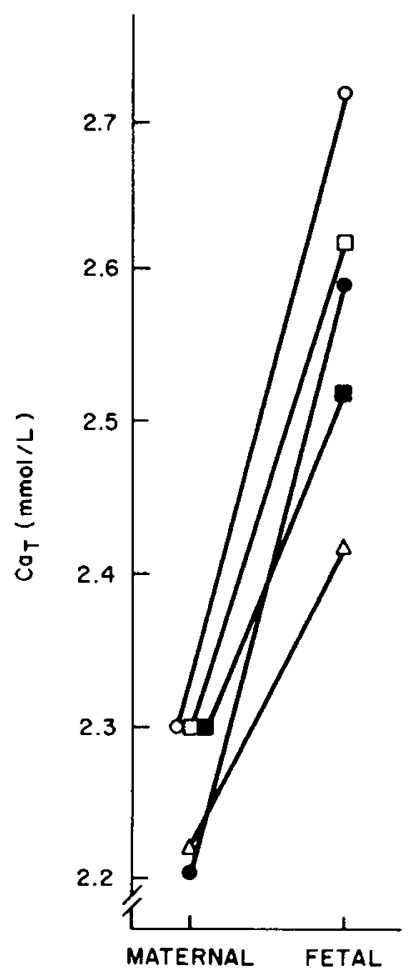

b

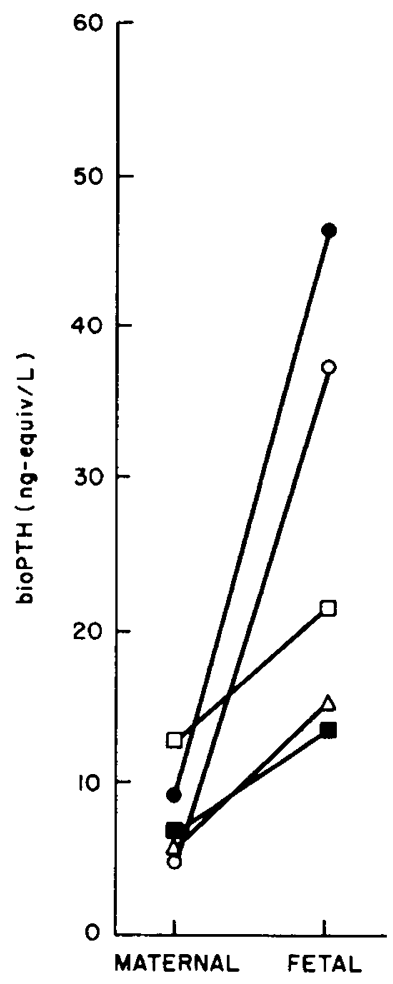

C

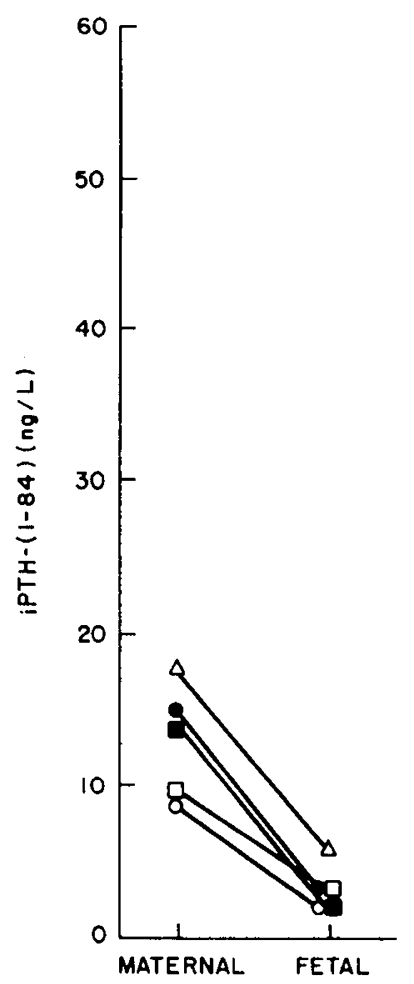

Fig. 2. Differences between paired maternal and fetal (umbilical) plasma samples with regard to $(a) \mathrm{Ca}_{\mathrm{T}},(b)$ bioPTH, and (c) iPTH-(1-84). Each maternal-fetal sample pair is represented by a different symbol. One converts ng/L of iPTH-(1-84) to pmol/L by multiplying by 0.1061 . The maternal bioPTH values (using a different standard) and iPTH-(1-84) values have been reported previously in ref. 25.

\section{DISCUSSION}

We have shown that levels of bioPTH that exceed those of normal adult subjects are present in human umbilical plasma from at least $26 \mathrm{wk}$ of gestation onward. The mean bioPTH concentration for the six normocalcemic adults is similar to the value obtained previously in a larger group of normal subjects (9.2 \pm 1.0 ng-equiv/L; $n=51)$ using a highly purified human PTH-(1-84) standard (Posillico JT, unpublished data). A striking feature of this bioactivity is that it also exceeds umbilical serum immunoreactive, intact PTH by 3- to 4-fold. By comparison, in newborn infants who are several days postpartum, as well as in normal nonpregnant adults and parturient women (25), iPTH(1-84) levels are $30-90 \%$ greater than bioPTH measured in corresponding samples. Because only minor deletions of the amino-terminus of PTH abolish biologic activity (31), it is quite possible that there are circulating forms of the hormone that are immunoreactive in the intact immunoradiometric assay but are not biologically active.

The discordantly elevated bioPTH concentrations measured in umbilical plasma might represent one or more PTH or PTHlike molecular species. Our detection system, the renal CBA, requires ligand binding to PTH-responsive receptors and subsequent stimulation of intracellular G6PD activity (20). Only PTH(1-84), N-terminal PTH fragments that contain at least amino acid residues 1-34 (6, 32), and PTHrP (33-36), an etiologic factor in the syndrome of humoral hypercalcemia of malignancy, are known to be stimulatory in this system.

PTH-(1-84) is the predominant biologically active form of circulating hormone both under physiologic conditions and in primary hyperparathyroidism $(37,38)$. The existence of measurable plasma concentrations of bioactive N-terminal PTH fragments has been controversial. Whereas parathyroid tissue may locally release $\mathrm{N}$-terminal fragments in addition to native hormone $(39,40)$, persistence of these forms in the circulation of normal individuals has not been detected. Furthermore, recent evidence suggests that circulating $\mathrm{N}$-terminal metabolites are not generated peripherally in vivo (41). In contrast, accumulation of $\mathrm{N}$-terminal fragments in plasma may occur during chronic renal failure with secondary hyperparathyroidism. In this disorder, Goltzman and associates reported that gel filtration of human (6) and canine (42) plasma reveals a significant fraction of the total plasma bioPTH coeluting with PTH-(1-34).

Intrauterine PTH metabolism, which might produce unique PTH profiles, has not been studied. Placenta (43), liver (44), and kidney are sites of local production of N-terminal metabolites of PTH and, therefore, are potential sources for production of circulating, $\mathrm{N}$-terminal fragments of $\mathrm{PTH}$ in utero.

Alternatively, some fraction of umbilical plasma bioPTH might represent circulating forms of PTHrP. Several fetal tissues in different species can synthesize PTHrP, including parathyroid, placental membranes $(45,46)$, and liver (47). Suggestively, human fetuses and patients with humoral hypercalcemia of malignancy do share certain biochemical features, viz. hypercalcemia, elevated bioPTH (48), and depressed iPTH-(1-84). However, when Goltzman et al. (48) preincubated plasma from patients with humoral hypercalcemia of malignancy with a multivalent antibovine PTH serum and then performed the CBA for PTH, significantly bioactivity remained. This finding contrasts with the results of our preincubation procedure, albeit using a different antibody that does appear to have limited cross-reactivity with $\mathrm{N}$-terminal PTHrP. We observed that this antiPTH antibody effectively quenches most activity of umbilical plasma in the CBA. Although low concentrations of PTHrP might circulate in umbilical plasma, the data do suggest that the predominant umbilical bioactive factors contain epitopes more closely related to PTH. We have not yet measured immunoreactive PTHrP in umbilical plasma. However, a recent report indicates that umbilical plasma has detectable but low levels of PTHrP compared with normal adults (49).

Our data may suggest a regulatory role for intrauterine bioPTH in maintenance of fetal calcium homeostasis during the third 


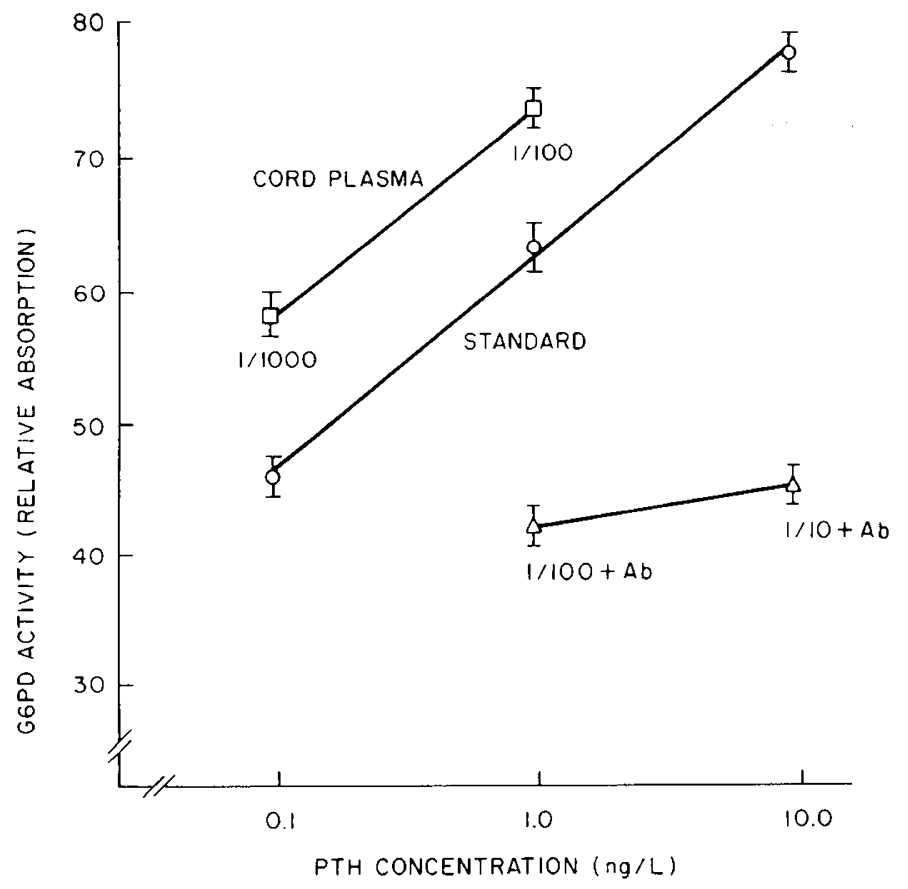

Fig. 3. Comparison of the effects of dilutions $(1 / 100$ and $1 / 1000)$ of cord plasma ( $\square$ ) and hPTH-(1-84) standard (O) on G6PD activity in guinea pig distal convoluted tubule cells. Enzyme activity, measured cytochemically as described in Materials and Methods, was expressed in terms of relative absorption determined by integrating microdensitometry. Each point represents the mean \pm SEM of 20 measurements from duplicate sections. G6PD activity of dilutions of cord plasma was parallel to that of the standard curve. Preincubation of cord plasma in the presence of antibovine PTH guinea pig serum (AS 211/41) $(\Delta)$ markedly reduced cytochemical bioactivity.

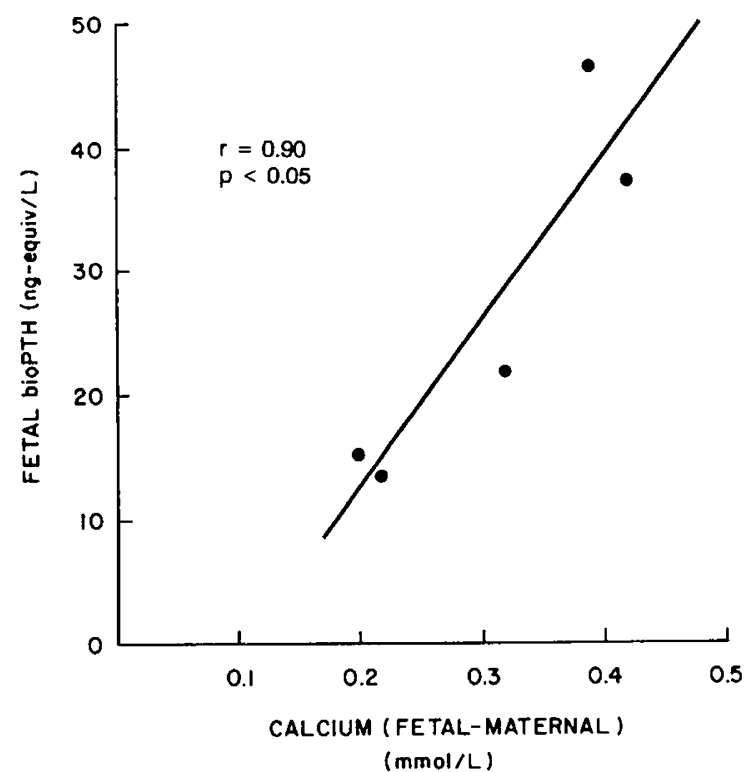

Fig. 4. Relation between umbilical venous plasma bioPTH and the difference between umbilical and maternal plasma calcium concentration. Samples were obtained from maternal vein and umbilical vein in five uncomplicated term births.

trimester. Low doses of PTH are known to stimulate bone formation in human adults $(50,51)$ and act as a mitogen for embryonic chondrocytes in vitro (52). Therefore, the maintenance of slightly elevated bioPTH levels in the fetal circulation, despite ambient hypercalcemia, suggests a potential anabolic role for the fetal skeleton. Conversely, the depressed umbilical

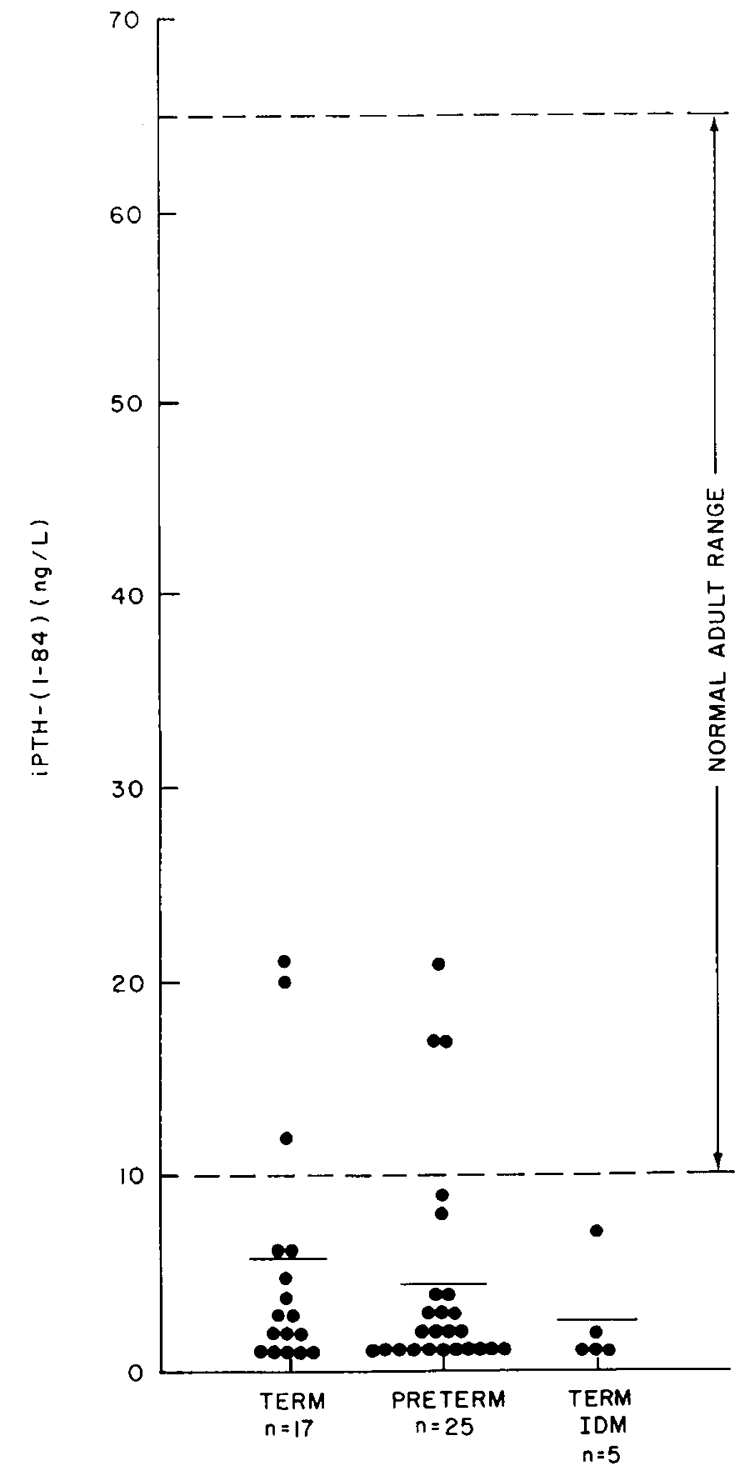

Fig. 5. Umbilical venous iPTH-(1-84) levels in nondiabetic term and preterm infants and term IDM. The mean values (horizontal bars) of the three groups did not differ significantly. The broken lines describe the adult normal range for iPTH-(1-84) established by Nichols Institute Diagnostics.

bioPTH levels observed in the IDM may contribute to the pathogenesis of the early hypocalcemia frequently associated with these infants. The five IDM studied at birth displayed a trend toward lower plasma magnesium concentrations than either the term or preterm nondiabetic infants. Hypomagnesemia and early neonatal hypocalcemia in IDM have been associated with depressed parathyroid function $(53,54)$.

Finally, whether or not the neonatal parathyroid gland can respond to a hypocalcemic stress has been a controversial point $(1,3,5,19)$. The preterm infants studied here were capable of elevating bioPTH and iPTH-(1-84) several-fold in response to dropping plasma $\mathrm{Ca}_{\mathrm{T}}$ and $\mathrm{Ca}_{1}$ concentrations. Indeed, the iPTH(1-84) levels observed for these $24-$ to 36 -h-old preterm infants are similar to maximal iPTH-(1-84) levels reported for normal adults infused with EDTA (55). Consequently, simple hypoparathyroidism does not appear to be the principal cause of early neonatal hypocalcemia in preterm infants.

Acknowledgments. The authors thank Drs. Douglas Richardson and Linda VanMarter for help with statistical analysis and Allison I. Caplan for technical assistance. 

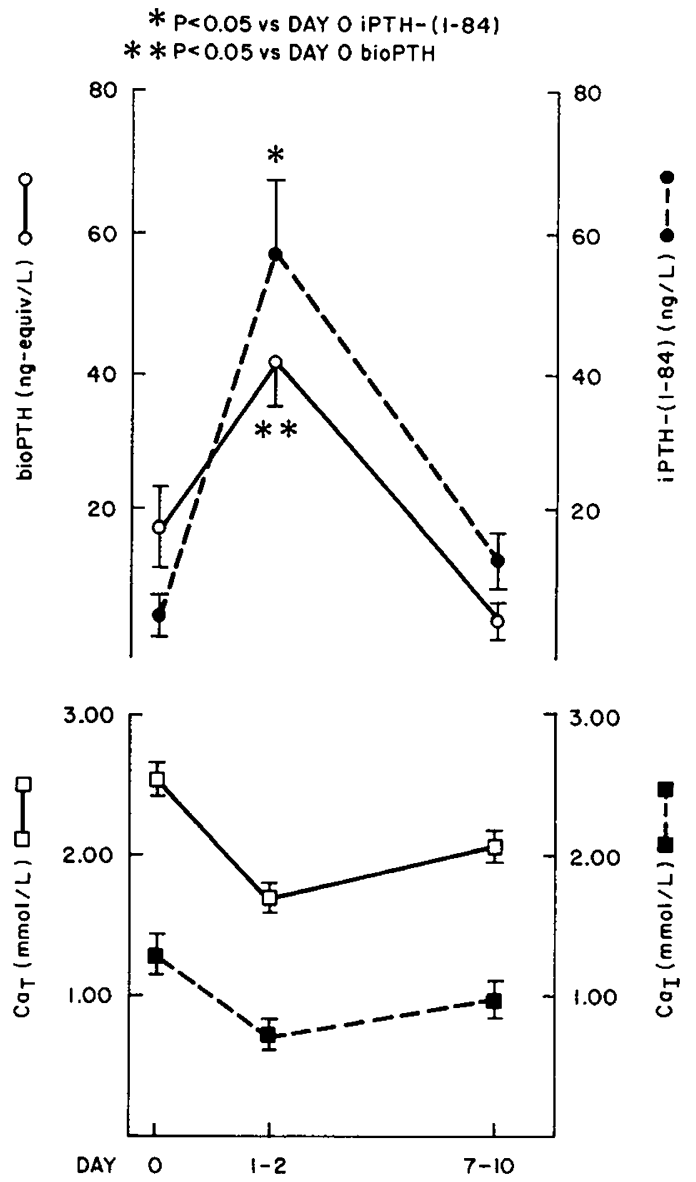

Fig. 6. Serial measurements of bioPTH (O), iPTH-(1-84) (-), Ca $(\square)$, and $\mathrm{Ca}_{1}(\square)$ in preterm newborns. Each point represents the mean $\pm \mathrm{SEM}(n=8)$. Samples were collected at the time of birth (umbilical venous plasma) and at 1-2 and 7-10 postnatal d. Both bioPTH and iPTH-(1-84) were significantly elevated at d 1-2 compared with the respective umbilical plasma values. Only the umbilical samples exhibited levels of bioPTH greater than iPTH-(1-84).

\section{REFERENCES}

1. Tsang RC, Light IJ, Sutherland JM, Kleinman LT 1973 Possible pathogenetic factors in neonatal hypocalcemia of prematurity. J Pediatr 82:423-429

2. Rosli A, Fanconi A 1973 Neonatal hypocalcemia "early type" in low birth weight newborns. Helv Paediatr Acta 28:443-457

3. Venkataraman PS, Tsang RC, Steichen JJ, Grey I, Neylan M, Fleischman AR 1986 Early neonatal hypocalcemia in extremely preterm infants; high incidence, early onset, and refractoriness to supraphysiologic doses of calcitriol. Am J Dis Child 140:1004-1008

4. Tsang RC, Chen I-W, Friedman MA, Chen I 1973 Neonatal parathyroid function: role of gestational age and postnatal age. J Pediatr 83:728-738

5. David L, Anast CS 1974 Calcium metabolism in newborn infants: interrelationship of parathyroid function and calcium, magnesium, and phosphorus in normal, sick, and hypocalcemic newborns. J Clin Invest 54:287-296

6. Goltzman D, Henderson B, Loveridge N 1980 Cytochemical bioassay of parathyroid homme: characteristics of the assay and analysis of circulating hormonal forms. J Clin Invest 65:1309-1317

7. Lindall AW, Elting J, Ells J, Roos BA 1983 Estimation of biologically active intact parathyroid hormone in normal and hyperparathyroid sera by sequential $\mathrm{N}$-terminal immunoextraction and midregion radioimmunoassay. J Clin Endocrinol Metab 57:1007-1014

8. Fairney A, Jackson D, Clayton BE 1973 Measurement of serum PTH, with particular reference to some infants with hypocalcemia. Arch Dis Child 48:419-424

9. Root A, Gruskin A, Reber RM, Stopa A, Duckett G 1974 Serum concentrations of parathyroid hormone in infants, children, and adolescents. J Pediatr 85:329-336

10. Hillman LS, Slatopolsky E, Haddad JG 1978 Perinatal vitamin D metabolism. IV. Maternal and cord serum 24,25-dihydroxy vitamin D concentrations. J Clin Endocrinol Metab 47:1073-1077

11. Reitz RE, Daane TA, Woods JR, Weinstein RL 1977 Calcium, magnesium, phosphorus, and parathyroid hormone interrelationships in pregnancy and newborn infants. Obstet Gynecol 50:701-705

12. Schedewie HK, Odell WD, Fisher DA, Krutzik SR, Dodge M, Cousins L, Fiser
WP 1979 Parathormone and perinatal calcium homeostasis. Pediatr Res $13: 1-6$

13. Nishiyama S, Fujimoto S, Kodama M, Matsuda I 1985 The negative correlation between prolactin and ionic calcium in cord blood of full term infants. Endocrinol Jpn 32:9-15

14. Allgrove J, Adami S, Manning RM, ORiordan JLH 1985 Cytochemical bioassay of parathyroid hormone in maternal and cord blood. Arch Dis Child 60:110-115

15. Lequin RM, Hackeng WHL, Schopman W 1970 A radioimmunoassay for parathyroid hormone in man. II. Measurement of PTH in human plasma by means of a radioimmunoassay for bovine hormone. Acta Endocrinol 63:655-666

16. Watney PJM, Rudd BT 1974 Calcium metabolism in pregnancy and in the newborn. J Obstet Gynaecol Br Commonw 81:210-209

17. Pitkin RM, Cruikshank DP, Schauberger CW, Reynolds WA, Williams GA, Hargis GK 1980 Fetal calcitropic hormones and neonatal calcium homeostasis. Pediatrics $66: 77-82$

18. Delvin EE, Salle BL, Glorieux FH, Adeleine P, David LS 1986 Vitamin D supplementation during pregnancy: effect on neonatal calcium homeostasis. J Pediatr 109:328-334

19. Venkataraman PS, Blick KK, Fry HD, Rao RK 1985 Postnatal changes in calcium-regulating hormones in very-low-birth weight infants: effects of early neonatal hypocalcemia and intravenous calcium infusion on serum PTH and calcitonin homeostasis. Am J Dis Child 139:913-916

20. Chambers DJ, Dunham J, Zanelli JM, Parsons JA, Bitensky L, Chayen J 1978 A sensitive bioassay of parathyroid hormone in plasma. Clin Endocrinol 9:375-379

21. Care AD, Ross R, Pickard DW, Weatherley AJ, Garel JM, Manning RM, Allgrove J, Papapoulos S, O'Riordan JLH 1982 Calcium homeostasis in the fetal pig. J Devel Physiol 4:85-106

22. Care AD, Caple IW, Singh R, Peddie M 1986 Studies on calcium homeostasis in the fetal Yucatan miniature pig. Lab Anim Sci 36:389-392

23. White $P 1949$ Symposium on diabetes mellitus: pregnancy complicating diabetes. Am J Med 7:609-616

24. Ballard JL, Novak KK, Driver M 1979 A simplified score for assessment of fetal maturity of newly born infants. J Pediatr 95:769-774

25. Davis OK, Hawkins DS, Rubin LP, Posillico JT, Brown EM, Schiff I 1988 Serum parathyroid hormone (PTH) in pregnant women determined by an immunoradiometric assay for intact PTH. J Clin Endocrinol Metab 67:850852

26. Fenton S, Somers S, Heath DA 1978 Preliminary studies with the sensitive cytochemical assay for parathyroid hormone. Clin Endocrinol 9:381-384

27. Posillico JT, Lobaugh B, Muhlbaier LH, Drezner MK 1985 Abnormal parathyroid function in the x-linked hypophosphatemic mouse. Calcif Tissue Int $37: 418-422$

28. Nussbaum SR, Zahradnik RJ, Lavigne JR, Brennan GL, Nozawa-Ung K, Kim LY, Keutmann HT, Wang CA, Potts Jr JT, Segre GV 1987 Highly sensitive two-site immunoradiometric assay of parathyrin, and its clinical utility in evaluating patients with hypercalcemia. Clin Chem 33:1364-1367

29. Scott SM, Ladenson JH, Aguanna JJ, Walgate J, Hillman LS 1984 Effect of calcium therapy in the sick infant with early neonatal hypocalcemia. J Pediatr 95:747-751

30. Venkataraman PS, Wilson DA, Sheldon RE, Rao R, Parker MK 1985 Effect of hypocalcemia on cardiac function in very low birth weight preterm neonates: studies of blood ionized calcium, echocardiography and assessment of cardiac effects of intravenous calcium therapy. Pediatrics 76.543-550

31. Habener JF, Rosenblatt M, Potts Jr JT 1984 Parathyroid hormone: biochemical aspects of biosynthesis, secretion, action, and metabolism. Physiol Rev 64:985-1053

32. Kent GN, Loveridge N, Reeve J, Zanelli JM 1985 Pharmacokinetics of synthetic human parathyroid hormone 1-34 in man measured by cytochemical bioassay and radioimmunoassay. Clin Sci 68:171-177

33. Broadus AE, Goltzman D, Webb AC, Kronenberg HM 1985 Messenger ribonuceic acid from tumors associated with humoral hypercalcemia of malignancy directs the synthesis of a secretory parathyroid hormone-like peptide. Endocrinology 117:1661-1666

34. Rabbani SA, Mitchell J, Roy DR, Kremer R, Bennett HPJ, Goltzman D 1986 Purification of peptides with parathyroid hormone-like bioactivity from human and rat malignancies associated with hypercalcemia. Endocrinology 118:1200-1210

35. Ikeda K, Mangin M, Dreyer BE, Webb AC, Posillico JT, Stewart AF, Bander NH, Weir EC, Insogna KL, Broadus AE 1988 Identification of transcripts encoding a parathyroid hormone-like peptide in messenger RNAs from a variety of human and animal tumors associated with humoral hypercalcemia of malignancy. J Clin Invest 81:2010-2014

36. Nakai M, Fukase M, Sakaguchi K, Noda T, Fujii N, Fujita T 1988 Human parathyroid hormone related protein fragment- $(1-34)$ has glucose-6-phosphate dehydrogenase activity on distal convoluted tubules in cytochemical bioassay. Biochem Biophys Res Commun 154:146-150

37. Martin KJ, Hruska KA, Freitrag JJ, Klahr S, Slatopolsky E 1979 The peripheral metabolism of parathyroid hormone. New Engl J Med 301:1092-1098

38. Goltzman D, Bennett MP, Koutsilieris M, Mitchell J, Rabbani SA, Rouleau MF 1986 Studies of the multiple molecular forms of bioactive parathyroid hormone and parathyroid hormone-like substances. Recent Prog Horm Res 42:665-703

39. Hanley DA, Takatsuki KT, Sulton JM, Schneider AB, Sherwood LM 1978 
Direct release of parathyroid hormone fragments from functioning bovine parathyroid glands in vitro. J Clin Invest 62:1247-1254

40. El-Hajj Fuleihan G, Chen CJ, Rivkees SA, Marynick SP, Stock J, Pallotta JA, Brown EM 1989 Calcium-dependent release of N-terminal fragments and intact immunoreactive parathyroid hormone by human parathyroid tissue in vitro. J. Clin Endocrinol Metab 69:860-867

41. Bringhurst FR, Stern AM, Yotts M, Mizrahi N, Segre GV, Potts Jr JT 1989 Peripheral metabolism of [35S] parathyroid hormone in vivo: influence of alterations in calcium availability and parathyroid status. $J$ Endocrinol 122:237-245

42. Grunbaum D, Wexler M, Antos M, Gascon-Barre M, Goltzman D 1984 Bioactive parathyroid hormone in canine progressive renal insufficiency. Am J Physiol 247:E442-E448

43. Balabanova S, Modinger C, Wolf AS, Teller WM 1986 Degradation of parathyroid hormone by placental homogenate. Acta Obstet Gynecol Scand 65:775-777

44. Pillai S, Zull JE 1986 Production of biologically active fragments of parathyroid hormone by isolated Kupffer cells. J Biol Chem 261:14919-14923

45. Loveridge N, Caple IW, Rodda C, Martin TJ, Care AD 1988 Further evidence for a parathyroid hormone-related protein in fetal parathyroid glands of sheep. Q J Exp Physiol 73:781-784

46. Abbas SK, Pickard DW, Illingworth D, Storer J, Purdie DW, Moniz C, Dixit M, Caple IW, Ebeling PR, Rodda CP, Martin TJ, Care AD 1990 Measurement of parathyroid hormone-related protein in extracts of fetal parathyroid glands and placental membranes. J Endocrinol 124:319-325

47. Ikeda K, Weir EC, Mangin M, Dannies PS, Kinder B, Deftos LJ, Brown EM, Broadus AE 1988 Expression of messenger ribonucleic acids encoding a parathyroid hormone-like peptide in normal human and animal tissues with abnormal expression in human parathyroid adenomas. Mol Endocrinol 2:1230-1236

48. Goltzman D, Stewart AF, Broadus AE 1981 Malignancy-associated hypercalcemia: evaluation with a cytobiological assay for parathyroid hormone. J Clin Endocrinol Metab 53:899-904

49. Khosla S, Johansen KL, Firek AF, Ory SJ, Kao PC 1990 Parathyroid hormonerelated peptide in lactation and in umbilical cord blood. Program and Abstracts of the Endocrine Society, 72nd Annual Meeting, p 1421(abstr)

50. Slovik DM, Neer RM, Potts Jr JT 1981 Short-term effects of synthetic human parathyroid hormone-(1-34) administration on bone mineral metabolism in osteoporotic patients. J Clin Invest 68:1261-1271

51. Slovik DM, Rosenthal DI, Doppelt SH, Potts Jr JT, Daly MA, Campbell JA, Neer RM 1985 Restoration of spinal bone in osteoporotic men by treatment with human parathyroid hormone $(1-34)$ and 1,25-dihydroxyvitamin D. J Bone Miner Res 1:377-381

52. Koike T, Iwamoto M, Shimazu A, Nakashima K, Suzuki F, Kato Y 1990 Potent mitogenic effects of parathyroid hormone (PTH) on embryonic chick and rabbit chondrocytes. Differential effects of age on growth, proteoglycans, and cyclic AMP responses of chondrocytes to PTH. J Clin Invest 85:626631

53. Tsang RC, Chen I-W, Friedman MA, Gigger M, Steichen J, Koffler H, Fenton L, Brown D, Pramanik A, Keenan W, Strub R, Joyce T 1975 Parathyroid function in infants of diabetic mothers. J Pediatr 86:399-404

54. Noguchi A, Eren M, Tsang RC 1980 Parathyroid hormone in hypocalcemic and normocalcemic infants of diabetic mothers. J Pediatr 97:112-114

55. Brent GA, LeBoff MS, Seely EW, Conlin PR, Brown EM 1988 Relationship between the concentration and rate of change of calcium and serum intact parathyroid hormone levels in normal human. J Clin Endocrinol Metab 67:944-950 